\title{
A CONSTITUIÇÃO E O DIREITO ADMINISTRATIVO
}

CAIO TÁCITO

O direito constitucional precede ao direito administrativo. Este tem como origem a limitação de poder que se inaugura com a submissão do Estado ao princípio da legalidade. É quando a norma jurídica igualmente obriga ao administrado e ao administrador que se pode constituir, com autonomia científica, uma área própria de conhecimento dedicada ao estudo do regime jurídico da administração pública.

No Estado absoluto a administração é um processo de gestão dos negócios públicos, sem que a ele se oponham direitos subjetivos dos administrados.

Os direitos do homem geram os deveres do Estado. Nos regimes absolutos, o administrador - veículo da vontade do soberano - é, como este, irresponsável. A administração é apenas uma técnica a serviço de privilégios de nascimento. O Estado de Direito, ao contrário, submete o poder ao domínio da lei: a atividade arbitrária se transforma em atividade jurídica. A lei, como expressão da vontade coletiva, incide tanto sobre os indivíduos como sobre as autoridades públicas. A liberdade administrativa cessa onde principia a vinculação legal. O executivo opera dentro de limites traçados pelo Legislativo e sob a vigilância do Judiciário.

Em face dessa realidade, avulta o papel da Constituição como o código do poder, o instrumento superior no qual se discriminam as competências e se definem as atribuições com respeito às diversas funções que incumbem ao Estado. Nela se identificam, conforme o regime político adotado, as incumbências da Administração na concretude dos princípios que emanam do sistema constitucional.

Ao direito administrativo cumpre traduzir na ação prática do Estado a efetividade das prestações, como das sujeições, que exprimem o conteúdo das relações de administração. Conforme a definição feliz de BENOIT, o direito administrativo é o direito público do quotidiano. ${ }^{1}$

1 Le Droit Administratif Français, 1968, pág. 3.

R. Dir. Adm.,

Rio de Janeiro, 232: 53-58,

Abr./Jun. 2003 
Quando a atividade administrativa passa a operar subordinada à imperatividade de um sistema jurídico é que se pode verdadeiramente falar em autonomia do direito administrativo.

Zanobini indica como certidão de nascimento do direito administrativo a lei revolucionária de 28 Pluviose, Ano VIIl (1800 no calendário gregoriano), que pela primeira vez atribuiu à administração francesa uma organização juridicamente garantida e externamente obrigatória. ${ }^{2}$

Mostra D'ALESSIO que a expressão "ato administrativo", de trânsito familiar na atualidade, aparece inovadoramente na terminologia da Lei de 16 Fructidor, Ano III (1796), quando interdita aos tribunais judiciários conhecer de atos da administração. ${ }^{3}$

Há, no plano histórico, uma identidade genética entre o princípio da separação de poderes - que forma o núcleo do Estado de Direito - e a especialização, no campo do direito público, de um ramo autônomo destinado especialmente ao tratamento jurídico da função administrativa.

O conceito clássico de Pellegrino ROSSI, no sentido de que no direito constitucional estão os títulos dos capítulos (têtes de chapitres) do direito administrativo, mereceu de BERTHELÉMY o aditamento de que "um é prefácio do outro", ${ }^{4}$ ou, conforme a imagem de Manoel Maria DIEZ, "o direito constitucional é a espinha dorsal do direito administrativo". 5

O direito administrativo é fruto. em suma, de um processo de autolimitação do Estado, na medida em que ele se institucionaliza e, por via de conseqüência, gera controles sobre sua própria atividade. Nesse sentido, Prosper WEIL qualifica a existência do direito administrativo como uma espécie de milagre: "nascido do milagre, o direito administrativo não sobrevive senão por um prodígio cada dia renovado" porque o Estado, ao menos em teoria, "pode pôr fim, quando assim desejar, à autolimitação em que consentiu". É a força da história e a permanência da sociedade organizada que formam a âncora em que se apóia a necessária continuidade de uma administração governanda pelo direito. ${ }^{6}$

Porque a noção do direito administrativo pressupõe a prévia organização política do Estado é que a sua matriz remonta ao direito constitucional, ou seja, à Constituição como fonte e essência do poder público.

O objeto do direito administrativo se concentra, dominantemente, na atividade do Poder Executivo. A execução das leis que a este poder incumbe primacialmente (até mesmo por sua etimologia) tem como destinação eminente a manutenção da ordem pública e o funcionamento dos serviços públicos.

A dimensão dessa atividade, as prerrogativas que são inatas, as prestações a que deve atender, as limitações que legitimamente pode impor aos particulares, os deveres a que deve acudir em benefício do interesse geral, em suma, toda a estrutura 
normativa dentro da qual vai agir a discricionariedade administrativa, encontram sua moldura nos comandos superiores da Constituição, ou seja, na missão constitucional da administração.

Dessa premissa indispensável à própria existência do direito administrativo decorre outra indagação, de extrema oportunidade nos momentos atuais.

Qual é a órbita própria de uma Constituição? Qual a matéria constitucional por sua natureza?

As Constituições não são necessariamente textos codificados nem tampouco bastam, por si mesmas, para esgotar os princípios fundamentais do Estado. Não há, na Inglaterra, uma Constituição escrita, mas nem por isso deixa de existir um definido sistema constitucional, cujas origens mergulham nos séculos, sob a inspiração primeira da Carta Magna. A Constituição francesa mais recente continua a ter como complemento o preâmbulo da Constituição anterior e, mais ainda, conserva, como um de seus principais subsídios, a Declaração dos Direitos do Homem, ideário da Revolução do Século XVIII.

De certo modo, diante da diversidade das cartas modernas e da extrema variação dos modelos políticos, que traduzem um mundo que se transforma, é mais fácil dizer-se o que não pode deixar de ser constitucional, do que tentar impor limites ao âmbito das Constituições.

A Constituição brasileira do Império, refletindo a doutrina da época, oferecia um parâmetro para a norma constitucional, assim conceituada no art. 178:

"É só constitucional o que diz respeito aos Limites e atribuições respectivas dos poderes públicos e aos direitos políticos e individuais dos cidadãos; tudo o que não é constitucional pode ser alterado, sem as formalidades referidas, pelas legislaturas ordinárias."

Desse modo, o trâmite especialmente prescrito na mesma Constituição para sua reforma quadrienal (arts. 174 a 177) não seria aplicado a não ser aos preceitos materialmente constitucionais, segundo a definição antes reproduzida.

A Constituição do Impérito resguardava a essência da Constituição em sua concepção clássica, e admitia pudesse a lei ordinária operar aquilo que a doutrina moderna veio a qualificar como o processo de desconstitucionalização da norma constitucional.

A sobriedade que, por essa forma, se preconizava (e da qual a Constituição norte-americana, em sua redação original, era um modelo perfeito) compatibilizava-se com as primícias do constitucionalismo, firmado nos princípios da separação de poderes e na garantia dos direitos individuais, sob o pálio dos valores fundamentais proclamados pela Revolução Francesa: liberdade, igualdade e fraternidade.

O Estado liberal nascente, estático por natureza, tinha como dogma a contenção do poder, ou antes, dos poderes que reciprocamente se disciplinavam, nos termos da consagrada fórmula de que "le pouvoir arrête de pouvoir". 
Ordenada a separação dos poderes constitucionais e sua órbita própria de influência e declarados os direitos fundamentais do homem, tudo o mais se remetia à competência ordinária dos Parlamentos, legitimados pelo princípio da representação popular.

A ordem social e política do século XIX, caracterizada pela estabilidade das instituições, repousava no individualismo jurídico, na igualdade de direitos, na liberdade do comércio e do contrato.

O Estado era tão-somente o árbitro afirmativo dos direitos individuais e das liberdades públicas, em um mundo presumidamente de pessoas iguais.

A Revolução Industrial, que lança raízes em meados do século passado, começa, no entanto, a desfazer esse idílico equilíbrio, pelo confronto entre as forças do capital e do trabalho. Uma nova ordem jurídica começa lentamente a evoluir sob a pressão de uma nova realidade econômica. Um sopro reformista perpassa tanto o direito público como os institutos tradicionais de direito privado. O Estado é convocado a disciplinar e conter os excessos do capitalismo e da propriedade privada, sujeitando-se aos princípios do bem comum e da justiça social. A tônica da atividade dos poderes públicos se desloca da abstenção para a intervenção.

Por via de consequiência, as Constituições se enriquecem com novos capítulos dedicados aos direitos econômicos e sociais deslocando o centro de gravidade da ordem jurídica. O Estado transforma sua presença, ultrapassando a simples garantia da liberdade individual para ambicionar a eficácia da segurança social.

Essa tendência tem como contrapartida a ampliação dos serviços públicos e, por efeito reflexo, a expansão do direito administrativo, instrumento por excelência da intervenção do Estado no domínio econômico e social. Dilata-se o poder de polícia, diversificam-se as pessoas administrativas, multiplicam-se as prestações do serviço público, de tal modo que, para um grande número de indivíduo, mais grave se torna a omissão do Estado, relapso em seus deveres, do que a ação ilícita da autoridade pública.

O papel do Estado, que antes se exprimia em deveres negativos (dever de não fazer ou não perturbar) e na garantia do livre exercício dos direitos individuais, passa a assumir deveres positivos (obrigações de fazer), a que correspondem pretensões dos administrados.

Tais deveres novos têm como fonte a nova roupagem das Constituições, às quais se acrescem títulos novos sobre a ordem econômica e social, em cujas bases a lei, o regulamento e a prática administrativa encontram alimento.

$O$ direito administrativo adquire, por essa forma, um desafio para o rejuvenescimento de seus conceitos e dos modelos adequados às novas missões do serviço público. A administração se descentraliza com a recepção de autarquias, sociedades de economia mista e empresas públicas; o conrole do poder discricionário se aprofunda com a valorização da finalidade na relação de administração, repudiando o desvio de poder; a regra da mutabilidade dos contratos administrativos torna mais flexível a ação administrativa ao mesmo tempo em que se generaliza o princípio da licitação; a responsabilidade civil do Estado se estende aos atos omissivos e se governa pela teoria do risco; o poder de polícia opera no sentido de tornar eficaz a 
função social da propriedade; o Estado se converte em empresário e chega ao monopólio de atividades econômicas essenciais.

O comando de uma nova ordem constitucional vai desembocar, em suma, em uma revisão e ampliação dos institutos de direito administrativo, na medida em que a administração representa o braço operante do Estado intervencionista.

Os direitos econômicos e sociais são um prolongamento dos direitos e liberdades individuais, contemplando a pessoa humana, além de sua qualidade pessoal para garantir seus direitos de participação na sociedade, substituindo um conceito de justiça distributiva pelo de uma justiça comutativa que deve levar em conta as desigualdades, ou seja, tratar desigualmente os desiguais, nos termos da lição de Rui Barbosa.

A personalidade do homem não se esgota, porém, nos limites da individualidade. Mais do que apenas uma pessoa, ele é também um participante da comunidade, cujos problemas se refletem em sua intimidade.

Surge, assim, em tempos atuais, uma nova tendência no sentido de ampliar o círculo dos direitos humanos de modo a abranger, além dos direitos de pessoas determinadas, o largo campo de direitos coletivos de categorias específicas, ligadas por uma relação comum, ou até mesmo os interesses de grupos sociais integrados por uma pluralidade de pessoas indeterminadas.

A vida moderna, sobretudo nos grandes centros urbanos, evidencia a importância de tais direitos sem titular certo, que, no entanto, se tornam essenciais ao bem-estar, e mesmo à sobrevivência de segmentos da sociedade.

As ofensas ao meio ambiente lesam o direito dos que nele convivem; aos consumidores sobreleva a qualidade dos produtos, o controle de preços ou a disponibilidade da oferta; o livre acesso à informação isenta ou a proteção de valores históricos e artísticos são meios elementares de difusão e preservação da cultura.

$\mathrm{Na}$ medida em que a Constituição passe a contemplar a existência de tais direitos, cumprirá ao direito administrativo propiciar os meios satisfatórios à consecução dos princípios e normas que se endereçam, mediante a prestação de serviços públicos especiais, ao atendimento de direitos e interesses multipessoais.

Tentamos esboçar, neste sumário, o fluxo de desenvolvimento do direito público que, partindo da oposição do poder absoluto mediante a afirmação de direitos e liberdades individuais, passou a defender, sucessivamente, os direitos sociais do homem, garantindo-lhe trabalho, saúde, educação e segurança contra a invalidez e o desemprego, e finalmente cuidando de impedir a espoliação dos recursos naturais e a violação dos bens da cultura. É certo que, em todo esse leque de garantias, o destinatário final continua a ser o homem, solitário ou em comunhão, defendido não apenas em seu patrimônio ou sua integridade física, como ainda em sua privacidade ou no direito de ser feliz. Contra a degradação da vida é que o direito opõe a força de sua tutela, visando a plenitude da fruição do bem-estar e da convivência, estendido o homem como um ser e um ente comunitário.

A Constituição é o grande painel dessa nova concepção de liberdade. É, contudo, na continuidade da administração que os direitos inscritos no plano superior da normatividade alcançam a perfeição da eficácia. A norma originária da constituição 
transita pela legislação derivada (leis e regulamentos) para alcançar a individualização de seus efeitos mediante a ação administrativa.

O direito constitucional e o direito administrativo se imbricam e se completam na prestação na prestação efetiva do Estado de Direito.

Assim como o direito administrativo encontra suas bases no antiplano das Constituições, estas se tornarão inoperantes, como meras Cartas de princípios, sem o socorro do direito administrativo, que fará do sonho a realidade, da norma programática a efetividade da prestação administrativa, como duas faces que se completam na concretização dos ideais de justiça e igualdade social.

No momento em que a sociedade brasileira está situada no limiar de uma nova ordem constitucional, é oportuno relembrar a harmonia entre os dois pólos do direito público.

Se a Constituição não deve ser repositório casuístico e meramente simbólico de atendimento dos agudos problemas dos diversos grupos sociais, é mister que nela se prescrevam as linhas mestras da política legislativa e, ao mesmo tempo, forneçam os instrumentos aptos a que, pela via administrativa, se possa atingir o desejável desiderato da justiça social.

Por essa forma, sobre as bases constitucionais se construirá a presença do direito administrativo.

A Constituição é o grande painel dessa nova concepção de liberdade. É, contudo, na continuidade da administração que os direitos inscritos no plano superior da normatividade alcançam a perfeição da eficácia. A norma originária da constituição transita pela legislação derivada (leis e regulamentos) para alcançar a individualização de seus efeitos mediante a ação administrativa.

O direito constitucional e o direito administrativo se imbricam e se completam na prestação efetiva do Estado de Direito.

Assim como o direito administrativo encontra suas bases no antiplano das Constituiçōes, estas se tornarão inoperantes, como meras Cartas de princípios, sem o socorro do direito administrativo, que fará do sonho a realidade, da norma programática a efetividade da prestação administrativa, como duas faces que se completam na concretização dos ideais de justiça e igualdade social.

No momento em que a sociedade brasileira está situada no limiar de uma nova ordem constitucional, é oportuno relembrar a harmonia entre os dois pólos do direito público.

Se a Constituição não deve ser repositório casuístico e meramente simbólico de atendimento dos agudos problemas dos diversos grupos sociais, é mister que nela se prescrevam as linhas mestras da política legislativa e, ao mesmo tempo, forneçam os instrumentos aptos a que, pela via administrativa, se possa atingir o desejável desiderato da justiça social.

Por essa forma, sobre as bases constitucionais se construirá a presença do direito administrativo. 